\title{
Os Parâmetros Curriculares Nacionais e o processo de constituição de uma didática da história para os anos iniciais.
}

\author{
The National Curricular Parameters and the process of constitution of \\ didactics of history for the initial years.
}

Tiago Costa Sanches ${ }^{1}$

RESUMO

O Ensino de História nos anos iniciais é um campo de pesquisa que, apesar de apresentar nos últimos anos um crescimento quantitativo e qualitativo, necessita de uma atenção especial dos pesquisadores e professores dos anos iniciais pela forma como tem sido abordado pelos organismos do Estado. Nos percursos de constituição da Didática da História nos anos iniciais, diversas concepções de ensino aprendizagem da História pautaram os debates sobre o tema, conferindo a esta Didática um caráter epistemológico específico. Preocupada em investigar os processos de construção do conhecimento histórico, utilizando a epistemologia específica da História, a linha de pesquisa Educação Histórica, apresenta hoje uma possibilidade de se pensar a Didática da Histórica a partir da própria ciência de referência. No entanto, considerando o exposto, o presente estudo buscou, em seu constructo teórico, explicitar as relações entre as ciências pedagógicas e a própria Ciência da História na constituição de uma didática específica da História para os anos iniciais. Atendendo esta especificidade o presente estudo contou com uma investigação empírica que, a partir da abordagem metodológica denominada Análise de Conteúdo, procurou investigar em documentos oficiais quais conce pções de ensino-aprendizagem balizaram sua construção. Deste estudo teórico e das análises de documentos oficiais nacionais, voltados para o Ensino de História, pode-se verificar al guns pressupostos e significados de uma Didática da História para os anos primeiros anos do Ensino Fundamental.

Palavras-chave: Ensino de História. Educação histórica. Didática da história. Anos iniciais.

\footnotetext{
${ }^{1}$ Universidade Federal da Integração Latino Americana (UNILA). Doutorado em Educação na UFPR.
} 


\begin{abstract}
Teaching History in the initial years is a field of research that, despite having presented quantitative and qualitative growth in recent years, needs special attention from the researchers and teachers of the initial years for the way it has been approached by the state organisms. In the course of the formation of Didactics of History in the initial years, several conceptions of teaching and learning of History guided the debates on the theme, giving these didactics a specific epistemological character. Concerned to investigate the processes of construction of historical knowledge, using the specific episte mology of History, the line of research Historical Education, presents today a possibility of thinking the Didactics of History from the science of reference. However, considering the above, the present study sought, in its theoretical construct, to explain the relations between the pedagogic sciences and the History Science itself in the constitution of a didactic specific of History for the initial years. Given this specificity the present study had an empirical investigation that, based on the methodological approach called Content Analysis, sought to investigate in official documents which conceptions of teaching and learning were its construction. From this theoretical study and from the analyzes of national official documents, focused on Teaching History, we can verify some assumptions and meanings of Didactics of History for the fi rst years of Elementary School.
\end{abstract}

Keyword: History Teaching. Historical education. Didactics of history. Early years.

As discussões e pesquisas sobre o Ensino de História nos anos iniciais no Brasil são escassas e tiveram início recentemente. A pesar de pouca produção na área, estes trabalhos apontam para uma crescente preocupação dos pesquisadores da área de Ensino de História em compreender os elementos que cercam o cotidiano dos professores e alunos dos anos iniciais quando se propõe a ensinar e aprender História, ampliando o espectro de investigação sobre tema nos programas de pós-graduação em todo o Brasil. Estas pesquisas têm anunciado um esforço dos pesquisadores da área em estabelecer uma relação entre as teorias historiográficas e o Ensino de História nos anos iniciais, no entanto, não se dispõe atualmente de pesquisas que se debrucem sobre a constituição de uma Didática da História destinada especificamente para os anos iniciais.

Este aumento nas pesquisas pode ser também observado em outros países e tem provocado o aparecimento de domínios específicos na área do Ensino de História, como o chamado campo da Educação Histórica que se desenvolveu em países como Inglaterra, Alemanha, Estados Unidos, Portugal e mais recentemente no Brasil. Uma prerrogativa destas pesquisas é a utilização da epistemologia específica da História nos processos investigativos, buscando nas discussões da Ciência da História. Estas discussões sobre aprendizagem histórica a partir da própria ciência de referência vêm sendo discutidas sistematicamente no campo da Educação Histórica, particularmente no âmbito do 
Laboratório de Pesquisa em Educação Histórica (LAPEDUH) da Universidade Federal do Paraná desde 1997.

Na esteira das reflexões precipitadas pelas pesquisas na área da Educação Histórica este trabalho busca responder, a partir dos resultados obtidos na tese de doutoramento, como se deu o processo de constituição de uma didática da História dos anos iniciais a partir da análise de documentos oficiais. Neste sentido, a pesquisa de doutoramento adotou como objeto de análise os documentos oficiais nacionais, responsáveis pela construção teórica e prática, da concepção de aprendizagem histórica presente nos ambientes de formação dos professores e nos processos de efetivação destas propostas em sala de aula. Neste trabalho em especial, será tomado como objeto de análise apenas um dos documentos analisados, portanto este artigo objetiva apresentar o processo de construção das concepções de aprendizagem histórica presentes nos Parâmetros Curriculares Nacionais (PCNs) de 1997 e documentos que foram utilizados em sua construção.

Para a análise dos documentos oficiais, a metodologia utilizada para a pesquisa empírica pautada na análise de conteúdo, proposta pela pesquisadora Maria Laura P. B. Franco, em sua obra de "Análise de conteúdo" (FRANCO, 2005).

Franco (2005) em seu trabalho busca ampliar a discussão acerca da Análise de Conteúdo e, para isso, a autora evidencia a importância de suas bases teóricas e metodológicas no contexto investigativo. Nesta perspectiva metodológica, o procedimento de pesquisa se situa em um delineamento mais amplo da teoria da comunicação e tem como ponto de partida a mensagem. A metodologia de investigação envolve três momentos distintos no trato com o documento, a análise, a interpretação e a inferência.

Ao utilizar a análise de conteúdo como referencial foram utilizadas as Unidades de Análise que podem ser divididas em Unidades de Registro e Unidades de Contexto. Dessa maneira, foram utilizadas no processo de análise dos dados as duas unidades, variando de acordo com a estrutura dos documentos.

Considerando a proposta metodológica de Franco (2005) investigar o contexto histórico social da produção de um documento é um importante momento de sua análise já que esta pode explicitar a complexidade do material analisado que envolve. Neste contexto investigativo, uma informação puramente descritiva não relacionada a outros atributos ou às características do próprio documento não devem compor as categorias de análise. Assim, toda a análise de conteúdo implica em comparações contextuais.

Desta maneira, cabe ressaltar que esta proposta metodológica se destaca por considerar a importância da subjetividade do pesquisador no trato das fontes, sem, no entanto, abandonar critérios de objetividade. 
A partir da definição das Unidades de Análise, de Registro ou Contextuais, faz-se necessário definir os critérios para as Categorias de Análise que podem ser definidas antes da apreciação do documento ou emergirem do próprio material pesquisado. A escolha pelo tipo de caracterização é realizada pelo pesquisador a partir do contato prévio com o objeto e não deve ser uma regra inflexível visto que, ao longo do processo de definição das categorias de análise, o pesquisador, na maioria dos casos, se encontra entre "constantes idas e vindas da teoria ao material de análise, do material de análise à teoria, e pressupõe a elaboração de várias versões do sistema categórico." (FRANCO, 2005, p. 58). Considerando a flexibilidade da definição das categorias de análise, cabe ressaltar que neste trabalho algumas dessas categorias surgiram na construção teórica da pesquisa. Entretanto, novas categorias surgiram posteriormente, no momento das análises, situação esta que levou a retomada constante de elementos teóricos.

Tomando o objeto e a metodologia de análise, cabe ressaltar que as orientações curriculares se referem a um determinado conhecimento escolar, um ti po especial de saber, ou seja, a História como matéria de ensino, que pode ser explicada pela ideia de uma larga tradição social inventada, não de uma só vez, e recriada no que o educador espanhol Raimundo Cuesta Fernandez (1998) denomina "código disciplinar".

Para este autor, a formação do código disciplinar se dá por meio de uma "tradição social que se configura historicamente e que é composta por um conjunto de ideias, valores, suposições e rotinas que legitimam a função educativa atribuída a História e que regulam a organização da prática de seu ensino" (CUESTA FERNANDEZ, 1998, p.8).

Neste sentido, pode se destacar duas perspectivas de análise do código disciplinar, a primeira toma como fonte a produção de currículos, orientações descritas na legislaçã o e manuais didáticos, estes elementos implicam na produção do que ele chama de "textos visíveis" do código disciplinar.

A segunda perspectiva de análise possível consiste em investigar os contextos escolares da prática de ensino, sendo este os "textos invisíveis". Segundo Urban (2009) para alcançarmos um exame consistente do código disciplinar da História é preciso um levantamento detalhado de fontes, tais como entrevistas com os professores, imagens de espaços escolares, manuais didáticos para alunos ou destinados aos professores, regulamentos, enfim, elementos que contribuam para a reconstituição das diversas formas de pensar o Ensino de História em seu contexto escolar.

Ao tomar a primeira perspectiva de análise, ou seja, os textos visíveis, a escolha dos Parâmetros Curriculares como objeto de pesquisa se justifica dada sua relevância nas transformações, advindas do processo de produção e implementação da proposta curricular no Brasil. Além disso, é importante ressaltar que a partir da introdução deste documento no contexto educacional brasileiro o Ensino de História nos anos iniciais adquire uma 
especificidade normativa curricular tornando-se um marco definidor desse projeto de reconstrução do código disciplinar da História. (SCHMIDT, 2012).

Para Bittencourt (2008), a constituição ou permanência das disciplinas escolares nos diversos currículos tem sido marcada por uma história de tensões entre grupos próximos às esferas do poder educacional. Por conseguinte, a elaboração dos PCNs ocorreu em meio a confrontos em torno das escolhas dos conteúdos e métodos da história como disciplina escolar e pode ser definido como um divisor de águas nas pesquisas sobre o tema. Portanto a inserção deste documento no cenário educacional foi tomada como elemento definidor no recorte temporal da pesquisa, além de formar parte do corpus de análise.

\section{Os Parâmetros Curriculares Nacionais(PCN's)}

Os Parâmetros Curriculares Nacionais propostos pelo Ministério da Educação (MEC) são documentos elaborados com a função de estabelecer normativas para a área da educação. Estes parâmetros influenciam na construção dos documentos Estaduais (Diretrizes Estaduais de Educação), Municipais (Diretrizes Municipais de Educação) e as Propostas Pedagógicas das escolas (projetos políticos pedagógicos- PPP).

No ano de 1997, a publicação dos Parâmetros Curriculares Nacionais (PCNs) volume V, destinado à disciplina de História e Geografia para o ensino fundamental, trouxe novos objetivos, conteúdos, métodos avaliativos e orientações didáticas que possibilitaram elementos constituidores de uma Didática da História para os anos iniciais.

A História como disciplina escolar experimentou no decorrer de sua existência diferentes concepções sobre o aprender e o ensinar, bem como diversas orientações para a prática do professor. Excluída e reintegrada em variados níveis de ensino a disciplina de História sofreu em sua trajetória de consolidação diversas transformações de cunho teórico e especialmente metodológico.

Apesar da inegável importância dos documentos na constituição do código disciplinar da História no Brasil não se pode atribuir aos documentos normativos a solução de todas as questões do ensino da disciplina. Portanto, o significado do termo currículo é dado pelo próprio contexto em que este se insere, sendo assim é sempre necessário problematizar a compreensão que se tem de currículo e suas implicações no espaço escolar. O que ocorre, muitas vezes, é que o documento curricular é concebido como uma "entidade", normativa 
que implicaria mecanicamente em novas práticas, no interior da escola, gerando constantes debates sobre sua eficácia.

Desse ponto de vista, pode-se compreender a frustração ou o espanto do dirigente educacional ou do político que, tendo determinado a produção da proposta curricular mais avançada, se obriga a afirmar que, apesar dela, o ensino não vai bem, por que os professores precisam aprender a ensinar dessa forma mais avançada e precisam de "capacitação". (SCHMIDT; GARCIA, 2001, p.147).

Esta "seleção" curricular é fruto de uma concepção de currículo, ou seja, na elaboração do documento, alguns referenciais teóricos foram adotados para contribuir na concepção de um currículo formal, dentre eles podemos citar Jean Claude Forquin (1993) Ivor Goodson (1991, 1995) e Antônio Flavio Moreira (1990).

Estes autores destacaram as particularidades dos documentos curriculares, "relacionando-os ao lugar institucional que o define como texto normativo, imprimindo um caráter oficial e fornecendo legitimidade a um determinado tipo de conhecimento" (BITTENCOURT, 2008, p.128).

Considerando as intenções e limites que um documento normativo oficial apresenta, buscou-se investigar no texto elementos que evidenciasse o processo de construção das concepções de ensino e aprendizagem histórica nos anos iniciais.

Publicado em meio à discussão política de redemocratização da educação, os PCNs se constituíram como um elemento aglutinador entre teorias educacionais e teorias historiográficas. Porém, além de ser concebido como um marco epistemológico, o documento surge como uma proposta de rompimento com o período militar, de renovação e de afirmação de um novo período.

Nas décadas de 1970 e 80, o Ensino de História sofreu influências de mudanças que aconteceram no sistema produtivo mundial que demandaram formas diferenciadas de organização social. A partir deste contexto de mudanças nas estruturas educacionais, o Ministério da Educação investiu na elaboração dos "Parâmetros Curriculares Nacionais" que atendesse as necessidades de um país em "desenvolvimento". Os Parâmetros Curriculares para o ensino fundamental foram estruturados a partir de objetivos gerais, nos quais cada área do conhecimento traria suas contribuições específicas.

O documento elenca seu principal objetivo como 
[...], sendo um dos mais relevantes o que se relaciona à constituição da noção de identidade. Assim, é primordial que o ensino de História estabeleça relações entre identidades individuais, sociais e coletivas, entre as quais as que se constituem como nacionais. (BRASIL, 1997, p. 26).

É interessante ressaltar que o elemento norteador das concepções anteriores, a identidade nacional, não é abandonado, entretanto a concepção de cidadania como elemento formado a partir da relação entre diferentes identidades passa a constituir o centro das discussões.

Percebe-se, portanto, que o elemento identidade individual, negado nas propostas curriculares anteriores passa a ser considerado na produção do documento de 1997. Neste sentido, é apresentada a possibilidade de entendimento da realidade social a partir do estudo da temporalidade dos confrontos entre povos, grupos e classes.

Os estudos consideram que, no confronto entre povos, grupos e classes, a realidade é moldada por descontinuidades políticas, por rupturas nas lutas, por momentos de permanências de costumes ou valores, por transformações rápidas e lentas. (BRASIL, 1997, p. 26).

Ao considerar que a História é marcada por lutas, confrontos e rupturas a concepção de aprendizagem histórica, pretendida pelo documento, rompe com a perspectiva anterior e busca inserir novas questões ao Ensino de História.

O documento propõe uma concepção de saber histórico, apresentando a distinção entre um saber histórico científico e um saber histórico escolar. Portanto, o saber histórico escolar reelabora o conhecimento produzido no campo das pesquisas dos historiadores e especialistas do campo das Ciências Humanas, selecionando e se apropriando de partes dos resultados acadêmicos, articulando-os de acordo com seus objetivos. Esta perspectiva está vinculada a ideia de Transposição Didática.

Verificou-se nas análises realizadas que, uma das principais características desta Didática da História específica para os anos iniciais, é a distinção epistemológica entre o conteúdo, o método e a finalidade do Ensino de História nos anos iniciais. Esta distinção 
revelou não apenas uma organização estrutural dos documentos, mas também uma escolha teórica e metodológica prévia. Neste sentido, a concepção de aprendizagem histórica foi estruturada a partir do ensino de três conceitos fundamentais: o de fato histórico, de sujeito histórico e de tempo histórico. A forma como estes conceitos são definidos e apropriados pelo documento revelou os conteúdos que deveriam ser aprendidos pelos alunos nas escolas.

\section{Elementos para uma didática da história nos anos iniciais}

As análises realizadas nos documentos oficiais foram pautadas pelas discussões teóricas que precederam a investigação empírica. As categorias que estruturaram as análises foram determinadas por aspectos verificados nos documentos que expressassem indicativos teóricos e metodológicos de uma didática específica para os anos iniciais. Verificou-se nos documentos analisados que os pressupostos desta didática foram compostos de três categorias norteadoras, sendo elas o que ensinar, como ensinar e por que ensinar história.

Tomando as Unidades de Registro como perspectiva de análise do conceito de saber histórico apresentado pelo documento, percebe-se com clareza o primeiro indício de uma concepção de ensino-aprendizagem histórica nos anos iniciais.

O ensino e a aprendizagem de História envolvem uma distinção básica entre o saber histórico, como um campo de pesquisa e produção de conhecimento do domínio de especialistas, e o saber histórico escolar, como conhecimento produzido no espaço escolar. (BRASIL, 1997, p. 29)

Durante o período da ditadura militar o Ensino de História foi pautado pela incorporação de aspectos relacionados aos métodos e técnicas de ensino provenientes de uma pedagogia tecnicista.

A partir do pressuposto da neutralidade científica e inspirada nos princípios de racionalidade, eficiência e produtividade, essa pedagogia advoga a reordenação do processo educativo de maneira a torná-lo objetivo e operacional. (SAVIANI, 2005, p.10). 
Percebendo a lacuna entre a produção historiográfica e o Ensino de História em sala de aula pesquisadores/professores de História buscam novas formas de pensar esta relação entre universidade e escola. Esta distinção entre saber histórico científico e saber histórico escolar proposta pelo documento pode ser entendida como uma tentativa de aproximar o conhecimento histórico científico do processo de ensino-aprendizagem, "na sala de aula, os materiais didáticos e as diversas formas de comunicação escolar apresentadas no processo pedagógico constituem o que se denomina saber histórico escolar." (BRASIL, 1997, p.29). Assim sendo, o saber escolar é construído a partir do estudo de novos materiais (relatos orais, imagens, objetos, danças, músicas, narrativas) sendo estes, ferramentas de construção do saber histórico escolar.

Segundo o documento, o saber histórico se relaciona com o saber histórico escolar a partir da delimitação de três conceitos fundamentais: o de fato histórico, de sujeito histórico e de tempo histórico. A forma como estes conceitos são definidos e apropriados pelo documento orientam a formação de uma concepção de aprendizagem histórica, envolvida no ensino da disciplina.

Segundo os PCNs os fatos históricos podem ser descritos como

[...] ações humanas significativas, escolhidas por professores e alunos, para análises de determinados momentos históricos. Podem ser eventos que pertencem ao passado mais próximo ou distante, de caráter material ou mental, que destaquem mudanças ou permanências ocorridas na vida coletiva. (BRASIL, 1997, p.29).

Estas ações humanas (criações artísticas, ritos religiosos, técnicas de produção, formas de desenho, atos de governantes, comportamentos de crianças ou mulheres, independências políticas de povos) seriam realizadas de forma individual, ou pelas coletividades envolvendo diferentes níveis da vida em sociedade sendo então selecionadas, pelo docente no momento da aula, por razão de seu destaque nas transformações sociais.

A inserção dos Estudos Sociais no lugar das disciplinas de História e Geografia, o modelo de Ensino de História predominante no Brasil, durante todo o período militar, teve como objetivo controlar os conteúdos de História a ser ensinado nas escolas advogando a favor daformação de cidadãos dóceis, obedientes e ordeiros (NADAI, 1993), provocando um "esvaziamento de conteúdos históricos". 
Ao analisar a definição do conceito de fato histórico proposto pelo documento sob a perspectiva temática (conceitual) da Análise de Conteúdo, nota-se mais uma vez a negação de uma concepção de ensino tradicional positivista e uma proposta de renovação dos conteúdos históricos, inserindo novos fatos históricos e por consequência novos sujeitos.

No intuito de romper com uma concepção "doutrinária" de se ensinar e aprender História, o documento passa a considerar a participação de novos sujeitos históricos como homens comuns, mulheres e crianças na História a ser ensinada nas escolas. Deste modo, outro conceito fundamental nesta nova concepção de ensino-aprendizagem da História, segundo o documento, seria o conceito de sujeito histórico.

Sujeitos históricos devem ser compreendidos por sua vez, como "agentes de ação social, que se tornam significativos para estudos históricos escolhidos com fins didáticos, sendo eles indivíduos, grupos ou classes sociais." (BRASIL, 1997, p.29). Novamente percebe-se a necessidade do documento em inserir na História ensinada elementos negados anteriormente. Sendo assim, sujeitos históricos seriam aqueles que, a partir de seus contextos sociais e temporais, atuaram como protagonistas nas transformações da sociedade de forma individual ou coletiva.

Nesta nova perspectiva de Ensino de História, defendida pelo documento, novos sujeitos passam a fazer parte da História, basta que tenham atuado como protagonistas em mudanças sociais e temporais. Ao analisar nova concepção de sujeito histórico, é possível afirmar que o documento busca uma nova perspectiva de se aprender História, já que pessoas ditas "comuns" passam a ser vistas como agentes históricos. Ou seja, múltiplas identidades devem ser inseridas na discussão e entendimento do passado.

O terceiro conceito, ou conteúdo histórico, apresentado pelo documento como fundamental ao Ensino de História é o tempo histórico, que não deveria ser entendido de forma limitada ao tempo cronológico, partindo de uma linha temporal apresenta uma sequência dos acontecimentos sugerindo equivocadamente,

[...] que toda a humanidade seguiu ou deveria seguir o mesmo percurso, criando assim a ideia de povos "atrasados" e "civilizados" e ainda limitando as ações humanas a uma ordem evolutiva, representando o tempo presente um estágio mais avançado da história da humanidade. (BRASIL, 1997, p. 30).

O uso do calendário, por exemplo, pode ser importante, pois "possibilita especificar o lugar dos momentos históricos na sucessão do tempo, mas procura trabalhar também com a 
ideia de diferentes níveis e ritmos de durações temporais". (BRASIL, 1997, p.30). Estes níveis e ritmos seriam ditados pela percepção das mudanças ou das permanências nas vivências humanas. Segundo o documento, o tempo histórico

[...] pode ser apreendido a partir de vivências pessoais, pela intuição, como no caso do tempo biológico (crescimento, envelhecimento) e do tempo psicológico interno dos indivíduos (idéia de sucessão, de mudança). (BRASIL, 1997, p.30).

Além desta perspectiva, o tempo pode ser compreendido também "como um objeto de cultura, um objeto social construído pelos povos, como no caso do tempo cronológico e astronômico (sucessão de dias e noites, de meses e séculos)." (BRASIL, 1997, p.30).

Nota-se nesta análise sobre a concepção de tempo histórico, um processo de subjetivação do tempo histórico. Neste sentido, o tempo da experiência do sujeito passa a ser considerado no processo de aprendizagem histórica o que aproxima esta concepção de aprendizagem das teorias psicológicas da aprendizagem. Complementando a concepção de tempo histórico, a ideia de diferentes níveis e ritmos de duração do tempo, fundamentados nas teorias da história, tomam espaço na discussão sobre o ensino da disciplina.

Observa-se que existe um empenho do documento em utilizar elementos da Teoria da História no processo de aprendizagem, entretanto a ideia de longa, média e curta duração temporal, advindos da Ciência da História ${ }^{2}$, devem então ser subjetivados pelo tempo psicológico interno dos indivíduos a partir das vivências pessoais, conceito "adaptado" da psicologia.

No processo de construção destes conceitos históricos, percebe-se novamente a preocupação que o documento apresenta em romper como os conceitos e concepções históricas utilizadas pelo projeto político educacional militar. Dessa forma, o documento defende a necessidade de fundamentar os currículos em "teorias renovadas"3 uma nova perspectiva de aprendizagem histórica, esta concepção provocou uma ampliação conceitual ao inserir novos elementos e conteúdos no processo de aprendizagem histórica.

Além de considerar a diversidade e os confrontos presentes no seio da sociedade, o documento, em função da expansão escolar para um público culturalmente diversificado, salienta que o Ensino de História não pode estar vinculado apenas às mudanças teóricas presentes na produção historiográfica, já que esta estaria encerrada na produção do

${ }^{2}$ Conceitos formulados por teóricos da Escola dos Annales que buscava contrapor a ideia de tempo linear positivista.

${ }^{3}$ Termo utilizado pelo documento. 
conhecimento histórico. Portanto, para o documento, o método de ensino não pode ficar restrito à epistemologia da História, devem-se então considerar as "contribuições pedagógicas - especialmente da Psicologia social e cognitiva - e propostas pedagógicas que defendem trabalhos de natureza interdisciplinar" (BRASIL, 1997, p.26).

Ao mesmo tempo em que o texto traz esta perspectiva renovadora em relação às teorias historiográficas os PCNs, buscam contribuições da psicologia da aprendizagem construtivista e se utilizam de conceitos de Piaget (psicologia genética), Vygotsky (teoria sociointeracionista) e Ausubel (aprendizagem significativa).

A orientação proposta nos Parâmetros Curriculares Nacionais reconhece a importância da participação construtiva do aluno e, ao mesmo tempo, da intervenção do professor para a aprendizagem de conteúdos específicos que favoreçam o desenvolvimento das capacidades necessárias à formação do indivíduo. (BRASIL, 1997, p.33)

Tomando a perspectiva construtivista de ensino-aprendizagem como fundamentação, o documento propõe que, a escola deveria dar condições para que o aluno desenvolva/descubra suas capacidades de modo a adquirir autonomia, raciocinando livremente sobre qualquer assunto e tendo como autoridade maior sua própria razão. Neste sentido, o conhecimento não pode se limitar a aquisição de conteúdos externos ou interpretações individuais, mas sim ser resultado de uma construção social e histórica de ordem cultural e psicológica. (BRASIL, 1997, p.37).

Segundo o documento, a aprendizagem conduz ao desenvolvimento por meio da atividade envolvida no processo de ensino, tendo-se em conta o papel dos fatores externos do desenvolvimento, com destaque especial à incorporação da cultura vivida em sua formação histórica, não como cultura dada. (LIBÂNEO, 2008).

Os instrumentos mediacionais aos quais os professores precisam recorrer para desempenhar bem sua profissão são as bases teóricoconceituais e metodológicas da ciência ensinada, as teorias pedagógicas, e as decorrentes metodologias, procedimentos e técnicas de ensino, a serviço da aprendizagem dos alunos na sala de aula. (LIBÂNEO, 2008, p. 61) 
Para a Análise de Conteúdo "uma questão temática incorpora, com maior ou menor intensidade, o aspecto pessoal atribuído pelo respondente acerca do significado de uma palavra e/ou sobre as conotações atribuídas a um conceito." (FRANCO, 2005, p.39). Assim como a distinção apresentada entre os conceitos de saberes históricos (escolares e científicos), o documento analisado, apresenta o conceito de conhecimento histórico também em seu caráter científico escolarizado.

O conhecimento histórico escolar, além de se relacionar com o conhecimento histórico de caráter científico nas especificações das noções básicas da área, também se articula aos fundamentos de seus métodos de pesquisa, adaptando-os para fins didáticos. (BRASIL, 1997, p.31).

Libâneo (2008) salienta que, no bojo das discussões sobre ensino-aprendizagem, persiste a ideia de uma didática que se desenvolva a partir da união dos processos de investigação da ciência (metodologia de pesquisa) aos produtos da investigação (conteúdos) pertinentes ao processo educativo. "Ou seja, o acesso aos conteúdos, à aquisição de conceitos científicos, precisa percorrer o processo de investigação, os modos de pensar e investigar da ciência ensinada." (LIBÂNEO, 2008, p. 79)

A partir desta perspectiva de didática, é possível compreender que o documento considera o processo de ensino-aprendizagem sob a ótica proposta por Libâneo, ou seja, para se trabalhar a construção do conhecimento histórico escolar é preciso partir dos métodos de pesquisa próprios da Ciência da História, métodos estes utilizados por historiadores na produção do próprio conhecimento histórico científico. Entretanto, cabe ressaltar que, o texto apresenta esta perspectiva como algo a ser adaptado à realidade escolar ou, como complementa a seguir, transposto didaticamente.

A transposição dos métodos de pesquisa da História para o ensino de História propicia situações pedagógicas privilegiadas para 0 desenvolvimento de capacidades intelectuais autônomas do estudante na leitura de obras humanas, do presente e do passado. (BRASIL, 1997, p.31). 
Percebe-se na proposição da transposição dos métodos de pesquisa da História para o ensino da disciplina das escolas mais um esforço de relacionar o Ensino de História à sua ciência de referência. No contexto de produção deste documento, pesquisadores interessados em retomar as discussões na área de pesquisa do Ensino de História iniciaram na década de 1980 uma possibilidade de diálogo entre a História e a Educação, aliando, assim, conceitos já existentes nos campos de conhecimento de origem.

Esta aproximação entre História e Educação teve como pressuposto a distinção entre saber acadêmico e saber escolar, sendo discutida a partir do conceito denominado Transposição Didática.

Percebe-se que a concepção de aprendizagem histórica foi escolarizada pela proposta do documento a partir da análise de três conceitos fundamentais: o de fato histórico, de sujeito histórico e de tempo histórico. A forma como estes conceitos são definidos e apropriados pelo documento revelou "o que" de fato deveria ser aprendido pelos alunos nas escolas.

Os conceitos históricos a serem ensinados na disciplina escolar de História, neste caso, foram previamente constituídos e delimitados não pelos professores ou a partir das necessidades ou carências de orientação dos alunos em sala de aula, mas por especialistas a partir da ideia Transposição Didática.

A segunda parte o documento apresenta especificações metodológicas para o primeiro e segundo ciclo de ensino e por último, orientações didáticas. Nesta parte o documento apresenta orientações de "como se aprende" e, portanto, "como se ensina"História nos anos iniciais.

Na parte destinada ao primeiro ciclo, ou seja, para a extinta primeira e segunda séries do Ensino Fundamental, o documento inicia com orientações para o ensino e aprendizagem de História, específicas para estas turmas.

O texto é principiado afirmando que mesmo as crianças pequenas ${ }^{4}$ recebem grande quantidade de informações sobre o mundo e que suas interpretações são fundadas no sendo comum, por isso caberia à escola e consequentemente ao Ensino de História interferir nestas interpretações para que estes alunos se tornem capazes de "compreender as semelhanças e as diferenças, as permanências e as transformações no modo de vida social, cultural e econômico de sua localidade, no presente e no passado, mediante a leitura de diferentes obras humanas." (BRASIL, 1997, p 39) de forma sistematizada.

O documento ressalta a importância do uso diversificado de fontes históricas, de preferência orais e iconográficas considerando que nesta idade os alunos ainda estão em fase de alfabetização. Outra indicação aos professores é que apresente aos alunos diferentes

${ }^{4} \mathrm{O}$ documento especifica a idade referente a cada ciclo no volume I dos Parâmetros Curriculares Nacionais. 
registros de fontes quanto à autoria e formas de marcação temporal, como calendários, contribuindo para que os alunos compreendam quem escreve a História e que desenvolvam a noção de ordenação temporal do seu cotidiano comparando acontecimentos "a partir de critérios de anterioridade ou posteridade e simultaneidade." (BRASIL, 1997, p.31).

Em seguida são apresentados os objetivos de História para o primeiro ciclo e de acordo com o documento espera-se que ao final do primeiro ciclo os alunos sejam capazes de:

\begin{tabular}{|l|}
\hline \multicolumn{1}{|c|}{ OBJETIVOS DE HISTÓRIA PARA O PRIMEIRO CICLO - PCN 1997} \\
\hline a) comparar acontecimentos no tempo, tendo como referência anterioridade, \\
posterioridade e simultaneidade; \\
\hline b) reconhecer algumas semelhanças e diferenças sociais, econômicas e culturais, \\
de dimensão cotidiana, existentes no seu grupo de convívio escolar e na sua \\
localidade;
\end{tabular}

Fonte: Brasil (1997, p.50).

No primeiro ciclo, pode-se verificar que dos sete objetivos da aprendizagem histórica três (a, c, f) apresentam alguma relação com o tempo e um cita o uso de fonte (g). Os demais objetivos (b, d, e) da aprendizagem histórica estão relacionados com o entendimento da diversidade social, econômica e cultural no tempo presente. 
Percebe-se que os objetivos da aprendizagem histórica estão relacionados a atividades/verbos que levem o aluno a identificar, reconhecer, comparar, caracterizar os documentos, as mudanças e permanências. Segundo Franco (2005), a partir de Unidades de Registro pode-se analisar mensagens, textos e documentos. Neste caso, as Palavras se tornam elementos que evidenciam uma ação orientadora ao receptor, ou seja, os objetivos a serem alcançados pelos alunos no processo de ensino orientam a prática do docente.

É importante ressaltar nos objetivos propostos a grande relevância dada aos acontecimentos do tempo presente e ao estudo de comunidades indígenas.

Em relação aos objetivos da aprendizagem histórica para o segundo ciclo espera-se que ao final deste período os alunos sejam capazes de:

\begin{tabular}{|l|}
\hline \multicolumn{1}{|c|}{ OBJETIVOS DE HISTÓRIA PARA O SEGUNDO CICLO - PCN 1997} \\
\hline a) $\begin{array}{l}\text { reconhecer algumas relações sociais, econômicas, políticas e culturais que a sua } \\
\text { coletividade estabelece ou estabeleceu com outras localidades, no presente e no } \\
\text { passado; }\end{array}$ \\
\hline b) identificar as ascendências e descendências das pessoas que pertencem à sua \\
localidade, quanto à nacionalidade, etnia, língua, religião e costumes, \\
contextualizando seus deslocamentos e confrontos culturais e étnicos, em diversos \\
momentos históricos nacionais;
\end{tabular}

Fonte: Brasil (1997, p.50).

No segundo ciclo, a questão do tempo está mais presente nos objetivos da aprendizagem histórica (a, b, c), o objetivo (d) aborda a questão da fonte e o objetivo (e) uma ação humana.

Tomando, primeiramente, como ponto de análise a questão temporal, verifica-se que o tempo aparece como elemento objetivo, apenas uma linha sequencial onde as mudanças 
(culturais, sociais, políticas) ocorrem. Este tempo, assim como no primeiro ciclo, objetiva ser reconhecido, identificado e comparado.

Neste aspecto, é nítida a presença da concepção do tempo histórico científico na aprendizagem histórica, os alunos devem ser capazes de colocar as mudanças e permanências em uma ordem temporal assim como faz o historiador ao produzir o conhecimento historiográfico. Portanto, para o documento, aprende-se História identificando, verificando, contextualizando as mudanças e permanências sociais e culturais na linha do tempo. Não obstante, as mudanças e permanências no tempo não são interpretadas pelo aluno, são apenas identificadas. O sujeito não mobiliza os interesses cognitivos pela carência de orientação, não atribui sentido as mudanças temporais e, por conseguinte não estabelece sua própria orientação temporal.

Neste sentido, apesar do documento ressaltar a importância do sujeito histórico no processo de aprendizagem, em relação à categoria tempo histórico, é identificada no documento uma concepção de aprendizagem histórica indiferente ao sujeito aprendiz, já que os interesses não partem de suas necessidades da vida prática e o conhecimento aprendido não é dotado de significado em sua orientação temporal.

No espaço destinado a orientação quanto à escolha dos conteúdos, mais uma vez o documento salienta a importância do Ensino da História estar fundamentado no desenvolvimento das noções temporais e suas implicações metodológicas de comparação.

A escolha dos conteúdos, por sua vez, que possam levar o aluno a desenvolver noções de diferença e de semelhança, de continuidade e de permanência, no tempo e no espaço, para a constituição de sua identidade social, envolve cuidados nos métodos de ensino. (BRASIL, 1997, p.31).

Assim como as orientações para a escolha dos conteúdos a serem ensinados nas escolas, os PCNs afirmam que, depois de os alunos vivenciarem situações de aprendizagem espera se que os alunos dominem além dos conteúdos os procedimentos, portanto, é preciso destacar alguns critérios para avaliar esses domínios. (BRASIL, 1997) Nota-se nos critérios de avaliação que o documento espera dos alunos a capacidade de reconhecer as mudanças e permanências, semelhanças e diferenças entre povos, culturas, lugares, classes entre outros.

É notável que o encaminhamento metodológico adotado pelos PCNs está bastante próximo da concepção teórico-educacional histórico cultural da aprendizagem apresentada por Libâneo (2008). A partir das discussões realizadas por Vigotsky, Leontiev e Davydov, 
sobre ensino desenvolvimental, Libâneo defende a renovação dos conteúdos da didática a partir da "busca de uma unidade entre uma teoria geral do ensino e as metodologias específicas, que estaria caracterizando o momento atual" (LIBÂNEO, 2008, p.63).

O documento apresenta uma proposta de formação crítica em relação à diversidade sociocultural, estabelecendo uma relação entre o presente e o passado de forma unidirecional, na qual o presente se apresenta como uma resultante do passado.

É importante destacar que a formação de um aluno crítico apresentada pelo documento é entendida no contexto histórico de sua produção como um significativo avanço em relação às concepções de aprendizagem histórica anteriores.

[...] os objetivos propostos visam à formação de um aluno critico, destacando, neste processo de formação, o presente como resultante do passado, e, em algumas propostas, uma preocupação que parece ser mais relevante é a de possibilitar a compreensão das diferentes temporalidades dos diversos grupos sociais e culturais. (BITTENCOURT, 2008, p.147).

Entretanto, analisando os objetivos de aprendizagem, nota-se que nesta concepção didática que a aprendizagem histórica fica restrita a própria atividade de aprender. Sendo assim, com base nos conteúdos da disciplina de História, aprender História significa, desenvolver capacidades e habilidades para que os alunos aprendam por si mesmos buscando soluções gerais para questões específicas e assim aplicar nas situações concretas.

Aprender historicamente seria então, desenvolver habilidades de pensar por meio dos conteúdos, e ensinar, seria a capacidade de desenvolver nos alunos o pensamento teórico, sendo este a "essência e o desenvolvimento dos objetos de conhecimento e com isso a aquisição de métodos e estratégias cognoscitivas gerais de cada ciência, em função de analisar e intervir nas situações concretas da vida prática." (LIBÂNEO, 2008, p. 79).

Para o documento, a aprendizagem histórica teria como finalidade a formação de um cidadão crítico, capaz de alcançar objetivos como analisar, identificar e comparar sua realidade com a realidade de comunidades diferentes, indígenas, por exemplo, ou de outras épocas. Esta habilidade, proposta pelo documento, em distinguir as diferenças e transformações socioculturais no tempo levaria os alunos a uma prática cidadã capaz de respeitar as múltiplas identidades e, portanto, superar práticas preconceituosas no convívio social. 
Apesar de o documento ressaltar a importância do estudo de outros períodos o texto enfatiza as atividades de comparação entre culturas, grupos, povos de lugares distintos sem considerar o aspecto temporal. Dessa forma, percebe-se uma preocupação maior em "capacitar" o aluno a identificar as diferenças sociais e culturais do que propriamente interpretar as mudanças e permanências históricas.

Cabe ressaltar que o objetivo deste trabalho não é apresentar críticas à concepção de aprendizagem histórica adotada pelo documento, mas sim buscar compreender quais matrizes teóricas fundamenta o processo de construção do documento.

Ao investigar os PCNs, percebeu-se uma distinção clara entre os conteúdos a serem ensinados e os métodos de ensino destes conteúdos. Nos espaços destinados a orientação quanto à escolha dos conteúdos o documento ressalta-se a importância do Ensino da História estar fundamentado no desenvolvimento das noções temporais e suas implicações metodológicas de comparação.

Esta concepção didática presente no documento buscou articular teorias que fundamentam os procedimentos científicos de produção do conhecimento históricos. Podese concluir, portanto, que no processo de produção destes documentos a cientificidade do conhecimento histórico esteve na pauta de discussão e acabou influenciando esta Didática da História nos anos iniciais.

\section{Considerações Finais}

As análises permitem afirmar que os documentos ressaltam a importância do sujeito histórico no processo de aprendizagem em relação aos conteúdos históricos, porém o enfoque na adequação do saber histórico produzido pelos historiadores em saber histórico escolar é mais forte do que na própria necessidade dos alunos em sala de aula.

Pode-se notar, ainda que o documento reforça a importância do estudo dos conteúdos em seu caráter histórico científico. Estas orientações epistemológicas estão descritas em seus textos e são enfatizadas em seus aspectos metodológicos, salientando que o ensino deve estar pautado em atividades de comparação entre culturas, grupos, povos de lugares distintos, no entanto estas comparações são desprovidas de um cunho histórico, ou seja, são realizadas isentas de temporalidade.

Neste sentido, vem sendo construída pelo ensino, desde as séries iniciais da escola fundamental, a partir das análises realizadas nos Parâmetros Curriculares Nacionais para os 
anos iniciais, uma concepção didática que entende o conhecimento histórico como algo imutável, indiferente a formação das capacidades cognitivas das crianças.

Rüsen afirma que "O aprendizado histórico depende da disposição de se confrontar com experiências que possuam um caráter especificamente histórico.” (RÜSEN, 2007b, p.111). Sendo assim, a experiência histórica consiste em o sujeito ter na experiência da mudança do tempo um elemento gerador de interesses pelo entendimento do passado, fundado em sua subjetividade propõe motivos para compreender o passado.

Desta forma

O sujeito desenvolve um sentido para a alteridade temporal e para os processos temporais, que o conduz do outro experimentado ao eu vivenciado, tornando esse eu muito mais consciente e conferindo lhe uma dinâmica temporal interna muito mais elaborada. (RÜSEN, 2007b, p.113)

Neste sentido, a aprendizagem dos conteúdos históricos perpassa pelo processo de apropriação das experiências humanas no tempo, sendo esta uma é uma preocupação Didática da História, pois é a partir da formação histórica que o sujeito pode ter acesso às variadas perspectivas de interpretação do passado.

Nota-se, nas análises dos critérios referentes ao processo de avaliação do Ensino de História nos anos iniciais, que os documentos esperam que os alunos desenvolvam a capacidade de reconhecer as mudanças e permanências, semelhanças e diferenças entre povos, culturas, lugares, classes entre outros.

Para o documento, a aprendizagem histórica teria como finalidade a formação de um cidadão crítico, capaz de alcançar objetivos como analisar, identificar e comparar sua realidade com a realidade de comunidades diferentes e de outras épocas.

Segundo o documento investigado, a aprendizagem histórica estaria subjugada ao domínio de habilidades cognitivas básicas como: observação, investigação, compreensão, argumentação, organização, memorização, analise, síntese, criatividade, comparação, interpretação e avaliação. Complementando estas habilidades, o documento orienta que os professores devem proporcionar aos alunos atividades que os levem a identificar e resolver problemas. 
Para os PCNs os alunos devem ser capazes de colocar as mudanças e permanências em uma ordem temporal assim como faz o historiador ao produzir o conhecimento historiográfico. Assim, aprende-se História identificando, verificando, contextualizando as mudanças e permanências sociais e culturais na linha do tempo. Não obstante, as mudanças e permanências no tempo não são interpretadas pelo aluno, são apenas identificadas. Foi expropriada do professor e do aluno a possibilidade de colocar o conhecimento histórico em perspectiva. A competência de interpretação do conteúdo histórico se estrutura em ter ciência da mutabilidade do conhecimento histórico. $O$ aumento da competência interpretativa proporciona uma melhora no aprendizado histórico conferindo ao sujeito aluno a capacidade de interpretar suas experiências históricas estipulando para estas experiências significados e distinguindo-as em função de critérios de importância.

O aprendizado histórico, com o aumento da capacidade interpretativa do sujeito, resulta em formação histórica no momento que os modelos de interpretação se tornam conscientes, organizados e tematizados com objeto de conhecimento. Este processo é dialético, pois na medida em que as experiências humanas no tempo são interpretadas, existe um ganho qualitativo não apenas no conhecimento objetivo em relação ao passado, mas se ganha também consciência de sua própria vida prática, ou como ressalta Rüsen (2001) na práxis formadora. Para Rüsen, a aprendizagem histórica é

Um processo de fatos colocados conscientemente entre dois polos, ou seja, por um lado, um pretexto objetivo das mudanças que as pessoas e seu mundo sofreram em tempos passados e, por outro, o ser subjetivo e a compreensão de si mesmo como a sua orientação no tempo. (RÜSEN, 2001, p.82)

Segundo o autor, a objetividade do conhecimento histórico é subjetivada pelo sentido que o aprendiz atribui ao passado. Ao mesmo tempo a atribuição de sentido ao passado é objetivada pela Ciência da História. "Este processo necessita uma apropriação mais ou menos consciente desta história, construir sua subjetividade e torna-la a forma de sua identidade histórica" (RÜSEN, 2007b, p.107).

Neste sentido, vem sendo construída pelo ensino, desde os anos iniciais da escola fundamental, uma concepção de Didática da História que entende o conhecimento histórico como algo imutável que pouco desenvolve as capacidades cognitivas das crianças. Esta concepção nega a aprendizagem do meio social, temporalmente localizado. (ABUD, 2002). 
Apesar da inserção de elementos da pesquisa historiográfica, como os conceitos de: fato histórico, sujeito histórico e tempo histórico, cultura, natureza, sociedade, relações sociais, poder e trabalho, a Didática da História se resume a métodos de ensino que muitas vezes foram "importados" de teorias de outras áreas do conhecimento. Estes métodos utilizados nos processos de aprendizagem histórica estão, portanto, situados fora da Ciência da História.

Portanto, afirma-se a partir das análises, que um dos pressupostos metodológicos da Didática da História para os anos iniciais é que a construção do conhecimento histórico pelos alunos em sala de aula deve ser orientada pelas teorias da psicologia da aprendizagem e teorias pedagógicas. Segundo Schmidt (2006, p.211)

$\mathrm{O}$ ato de situar os processos de cognição fora da epistemologia da História, contribuir para a predominância da pedagogização nos modos de aprender, o que produziu uma aprendizagem por competências que exclui competências históricas propriamente ditas.

Esta "pedagogização", apresentada por Schmidt, provocou uma organização didáticopedagógicas dos conteúdos históricos sem antes considerar uma análise epistemológica detalhada dos mesmos. Assim, ao desconsiderar o conteúdo como objetos da ciência de referência, a ser ensinado, seus procedimentos metodológicos foram gradativamente fundamentados nas teorias do conhecimento, na psicologia do desenvolvimento e na taxionomia dos objetivos. Neste sentido, Abud (2002, p. 557) contextualiza estas propostas afirmando que

As propostas curriculares para o período inicial trazem ainda uma certa saudade dos anos 70 e de uma valorização excessiva da Psicologia que se entranhou em documentos curriculares e que, em alguns programas chegou a secundarizar a própria disciplina, dando-lhe características que a afastaram dos princípios básicos da ciência de referência.

Para a autora, a influência de documentos produzidos na década de 1970, como os Guias Curriculares para o Ensino de Primeiro Grau ${ }^{5}$ são ainda hoje perceptível, no processo de constituição de propostas curriculares e livros didáticos de História.

${ }^{5}$ Elaborados para atender as exigências das novas Diretrizes e Bases da Educação Nacional, (5692/71) trazia os currículos para a nova organização escolar criada pela Lei, que introduzia o ensino de oito anos e transformava as disciplinas de História e Geografia em Estudos Sociais. 
Segundo Schmidt (2012, p. 100) esse processo

[...] caracterizou-se, principalmente, pela incorporação de aspectos relacionados aos métodos e técnicas de ensino e aos estudos referentes à personalidade e psicologia do educando, importados da Psicologia e da Didática Geral, indicando a existência de um novo tipo de conhecimento ou de uma didática específica, cujos conteúdos destinavam-se ao ensino e aprendizagem da história.

Considera-se que, a partir das análises e interpretações realizadas em documentos oficiais, a constituição de uma Didática da História para os anos iniciais foi marcada por diferentes concepções teóricas e metodológicas incluindo os processos de escolha dos conteúdos e principalmente os métodos de ensino. Estes métodos apontados desconsideram um elemento fundamental no processo de aprendizagem.

Sendo assim, é possível concluir a partir das análises que, um dos pressupostos metodológicos da Didática da História, para os anos iniciais, foi fundamentado pelas teorias da psicologia da aprendizagem e teorias pedagógicas. Neste sentido, a construção do conhecimento histórico em sala de aula deve ser orientada por métodos não históricos.

Os Parâmetros Curriculares Nacionais apresentam como função da aprendizagem histórica a formação de um cidadão crítico, capaz de alcançar objetivos como analisar, identificar e comparar sua realidade com a realidade de comunidades diferentes. Tomando a finalidade da aprendizagem histórica como um dos pressupostos de uma Didática da História para os anos iniciais, pode se afirmar que esta didática específica foi constituída a partir da ideia de formação de uma cidadania forjada a partir do estudo das diversas e múltiplas realidades existentes na sociedade, da experiência do presente, proporcionando ao aluno uma compreensão ativa de seu meio social, tornando este sujeito um cidadão crítico.

A teoria de aprendizagem histórica, desenvolvida pela teoria da consciência histórica de JörnRüsen, permite compreender, a partir da filosofia da história, os processos cognitivos do pensamento histórico. Segundo Schmidt (2006), o Ensino de História deve estabelecer uma relação inseparável com o método e a filosofia da própria Ciência da História, relação esta que possibilita pensar os objetivos e finalidades da a prendizagem histórica.

Assim sendo, para Rüsen (2001, p. 79) aprendizagem histórica 
É a consciência humana relativa ao tempo, experimentando o tempo para ser significativa, adquirindo e desenvolvendo a competência para atribuir significado ao tempo.

Para isso deve-se recuperar como se dá a partir da teoria da consciência histórica o processo de aprendizagem histórica. O diálogo entre as três dimensões temporais é inevitável no processo de aprendizagem histórica. Para o autor o presente é resignificado pela memória do passado para a construção das expectativas futuras.

A competência para orientação diz respeito à função prática das experiências interpretadas. Segundo Rüsen (2007b, p.116):

A competência histórica de orientação é a capacidade dos sujeitos de correlacionar os modelos de interpretação, prenhes de experiência e saber, com seu próprio presente e com sua própria vida, de utilizá-los para refletir e firmar posição própria na vida concreta no presente.

Orientar-se no tempo, por meio da aprendizagem histórica, adquire um caráter sistemático, racional e consciente. As três competências acima descritas são intimamente ligadas e definem as dimensões de aprendizado histórico e os níveis de complexidade da consciência histórica.

A atividade da consciência histórica pode ser considerada como aprendizado histórico quando produza ampliação da experiência do passado humano, aumento da competência para a interpretação histórica dessa experiência e reforço da capacidade de inserir e utilizar interpretações históricas no quadro de orientação da vida prática. (RÜSEN, 2007b, p.110)

A partir da premissa que a consciência histórica é suma das operações mentais da qual o sujeito interpreta suas experiências no tempo, esta competência se torna subjetiva e possível de se demonstrar mais ou menos articulada com o passado histórico podemos conferir a narrativa histórica do mesmo sujeito diferentes formas de atribuição de sentido, que variam 
de acordo com a capacidade de orientação no tempo. Seriam estas formas distintas de geração de sentido histórico que são constatadas, muitas vezes, na mesma narrativa histórica.

$\mathrm{Na}$ tentativa de responder as questões elencadas anteriormente pode-se afirmar que a construção da Didática da História específica para os anos iniciais foi constituída não a partir de uma concepção única de ensino-aprendizagem, mas do diálogo entre várias perspectivas teóricas e metodológicas. Neste sentido cabe ressaltar que, em uma análise ampliada desta didática específica, o processo de ensino-aprendizagem da História foi desmembrado em diferentes "etapas".

A partir dos pressupostos e significados teóricos e metodológicos de uma Didática da História específica para os anos iniciais pode-se concluir que, a partir de seu percurso de constituição, houve um processo de segmentação das dimensões do ensino e, por conseguinte da aprendizagem Histórica. Esta fragmentação foi forjada pela pluralidade de concepções teóricas e metodológicas presentes na construção dos princípios de como, o que e por que ensinar História.

Como consequência da análise realizada nos documentos oficiais, é possível afirmar que no percurso de construção de uma concepção didática específica para os anos iniciais, o processo de ensino-aprendizagem da História, foi fragmentado e instrumentalizado pela diversidade de concepções envolvidas nesta produção.

Esta fragmentação foi verificada no processo de consolidação de uma Didática da História presentes nos documentos oficiais, que orientam o ensino e a aprendizagem nos anos iniciais. Neste processo de consolidação, primeiramente pensou-se na escolha do conteúdo, a partir de uma visão historiográfica, em seguida buscou-se nas teorias pedagógicas e psicológicas formas e métodos de ensino deste conteúdo e por fim definiu-se como finalidade deste processo a formação de um cidadão consciente de seus direitos e deveres, apto a viver em sociedade.

Pode-se concluir, portanto, que no percurso de constituição desta didática específica não foi levado em consideração o fato de que o método de ensino da História "pressupõe uma relação intrínseca com o método e a filosofia da própria ciência, o qual delimita, não somente os objetivos e finalidades do ensino, mas também a sua forma de ensinar."(SCHMIDT, 2006, p. 4107).

Ao tomarmos a perspectiva da teoria da consciência histórica, apresenta-se como um novo pressuposto de uma Didática da História para os anos iniciais que a aprendizagem histórica busque na própria Ciência da História seus significados. 
Considerando os resultados obtidos nesta trajetória investigativa, cabe considerar que, em termos prospectivos, podem-se apontar diversas possibilidades de pesquisas que amplie o entendimento da Didática da História nos anos iniciais a partir da própria ciência de referência.

\section{Referências}

ABUD, Kátia Maria. Processos de construção do saber histórico escolar. História e Ensino, Londrina, v. 11, p. 25-33, jul., 2005.

_. Currículos de História e políticas públicas: os programas de História do Brasil na escola secundária. In: BITTENCOURT, Circe. (Org.). O saber histórico na sala de aula. 7. ed. São Paulo: Contexto, 2002. p. 28-41.

BITTENCOURT, Circe M. Fernandes. Ensino de história:fundamentos e métodos. 2. ed. São Paulo: Cortez, 2008.

BRASIL. MEC/SEF. Parâmetros Curriculares Nacionais: História. Brasília: 1997.

BRASIL. MEC. Plano Decenal de Educação para Todos. Brasília, 1993.

FERNANDEZ CUESTA, Raimundo. Clio enlas aulas: laenseñanza de lahistoriaenEspaña entre reformas, ilusiones y rutinas. Madrid: Akal, 1998.

FORQUIN, Jean-Claude. Escola e Cultura: As bases sociais e epistemológicas do conhecimento escolar. Porto Alegre: Artes Médicas, 1993.

FRANCO, Maria P.B. Análise de Conteúdo. 2. Ed. Brasília: Líber Livro, 2005.

GOODSON, Ivor. La construcción social del curriculum: possibilidade y âmbitos de investigación de la historia del curriculum. Revista de Educación, n. 295, n. 1, p. 7-37, 1991.

GOODSON, Ivor F. Currículo: teoria e história. Petrópolis: Vozes, 1995.

LIBÂNEO, José C. Didática e epistemologia: para além do embate entre a Didática e as didáticas específicas. In: VEIGA, Ilma Passos A.; D’ÁVILA, Cristina (Org.). Profissão docente: novos sentidos, novas perspectivas. Campinas: Papirus, 2008. p. 59-88.

MOREIRA, Antônio Flávio B. Currículos e programas no Brasil. Campinas: Papirus, 1990. 
NADAI, Elza. O Ensino de História no Brasil: Trajetória e Perspectiva. Revista Brasileira de História, São Paulo, v. 13, n. 25/26, p. 143-162, set.92 / ago.93.

RÜSEN, Jörn. Razão Histórica. Teoria da História: Os fundamentos da ciência histórica. Brasília: Ed. Universidade de Brasília, 2001.

. Reconstrução do Passado. Teoria da História II: os princípios da pesquisa histórica. Brasília: Ed. Universidade de Brasília, 2007a.

. História Viva. Teoria da História III: Formas e Funções do Conhecimento Histórico. Brasília: Ed. Universidade de Brasília, 2007b.

SAVIANI, Dermeval. As concepções pedagógicas na história da educação brasileira. Campinas, 25 ago, 2005. Disponível em: <http// www.histedbr. fae. unicampi. br/ navegando artigos_frames/artigo_036.html> .Acesso em: 29 jul. 2014.

SCHMIDT, Maria Auxiliadora. Contribuições ao estudo da construção da didática da história como disciplina escolar no Brasil: 1935-1952. In: CONGRESSO LUSO-BRASILEIRO DE HISTÓRIA DA EDUCAÇÃO: Percursos e desafios da pesquisa e do ensino de história da educação, 6., 2006, Uberlândia. Anais... Uberlândia: UFU, 2006. p.4100-4109. disponível em: <www.faced.ufu.br/colubhe06/anais/ arquivos/eixo6.htm>. Acesso em: 12 nov. 2011.

_ - _ _ _. Cultura histórica e cultura escolar: diálogos a partir da educação hi stórica. História Revista, Goiânia, v. 17, n.1, p. 91-104, jan./jun. 2012.

SCHMIDT, Maria Auxiliadora; GARCIA, Tânia M. F. Braga. Discutindo o currículo É por dentro. Educar em Revista. Dossiê Cultura e Escola: saberes, tempos e espaços como dimensões do currículo. Curitiba, n. 17, p. 139-149, jan./ jun. 2001.

URBAN, Ana Claudia. Didática da História: percursos de um código disciplinar no Brasil e na Espanha. 2009. Tese (Doutorado em Educação) - Universidade Federal do Paraná, Curitiba 2009.

Recebido em 16.08.2016

Aprovado em 20.09.2016 